\title{
Inheritance of Resistance to Fusarium Wilt in Sweet Basil
}

D. Chaimovitsh, N. Dudai, and E. Putievsky, Department of Aromatic and Medicinal Plants, ARO, Newe Ya'ar Research Center, P.O. Box 1021, Ramat Yishay 30095, Israel; and A. Ashri, Department of Field Crops, Vegetables and Genetics, Faculty of Agriculture, Food and Environmental Sciences, Hebrew University of Jerusalem, Rehovot, Israel

\begin{abstract}
Chaimovitsh, D., Dudai, N., Putievsky, E., and Ashri, A. 2006. Inheritance of resistance to Fusarium wilt in sweet basil. Plant Dis. 90:58-60.

Fusarium wilt, caused by Fusarium oxysporum f. sp. bacilici, is a severe disease of sweet basil (Ocimum basilicum L.) and has become acute mainly due to the intensive monoculture in greenhouses and, recently, to prohibition of methyl bromide application. In a previous work, we selected a resistant cultivar, Nufar, to address this problem. The mode of inheritance of resistance to $F$. oxysporum f. sp. bacilici in sweet basil was examined in progenies derived from crosses of the homogeneous resistant cv. Nufar and the susceptible homogenous cv. Chen. Artificial inoculation of seedlings with a high concentration of a microconidial suspension of a virulent isolate of $F$. oxysporum f. sp. bacilici revealed no difference between reciprocal backcrosses. The nuclear resistance analysis and dominant characteristics of the resistance of backcross progenies of different parental lines and the segregation for resistance in $\mathrm{F}_{2}$ combinations fitted the expected Mendelian ratio for a single dominant gene with two alleles that confer resistance to Fusarium wilt in basil. These results indicate the usefulness of utilizing this resistance to $F$. oxysporum $\mathrm{f}$. sp. bacilici in the production of new hybrids and cultivars of basil.
\end{abstract}

Sweet basil (Ocimum basilicum L.) is widely used as a fresh or dry herb and spice, a source for essential oil, and in traditional medicine. It is cultivated commercially in the Mediterranean region, the United States, and many other parts of the world $(4,10)$. In Israel, sweet basil is grown year round in polyethylene-covered greenhouses as a fresh herb for export (9). One of the major limitations caused by the monoculture cultivation of sweet basil is Fusarium wilt, caused by Fusarium oxysporum f. sp. basilici. The pathogen is specific to the host (6) and is virulent only in relation to $O$. basilicum (9). It is a limiting and destructive factor for this crop, and can cause partial to complete loss of yield and quality $(3,11)$. Fusarium wilt causes stunting of the plant, browning of the vascular tissue, and premature defoliation (9). The disease has been known since 1956 (12) and occurs in Russia, Italy, and France (4); it also has appeared in several states in the United States $(2,6,13)$ and in Israel (3). The worldwide expansion of cultivated areas of sweet basil, including

Corresponding author: N. Dudai

E-mail: nativdud@volcani.agri.gov.il.

Contribution No. $105 / 2005$ of the Agricultural Research Organization, the Volcani Center, Bet Dagan, 50-250 Israel.

Accepted for publication 8 August 2005.

DOI: 10.1094/PD-90-0058

(C) 2006 The American Phytopathological Society the United States and Israel, has been accompanied by a corresponding increase in the disease. The control of this pathogen in intensive monoculture conditions is carried out mostly by uprooting an old crop and replacing it with new seedlings. Control measures are limited to solar disinfestation combined with the addition of chemicals such as metham sodium or disinfestation with methyl bromide. During the growing season, there is no method of chemical or biological control against $F$. oxysporum $\mathrm{f}$. sp. bacilici, except sanitation of greenhouses by removal of infected plants to prevent the pathogen from spreading to other plants in the greenhouse $(3,7)$.

In Israel, some unaffected plants were rescued from a field which was severely infested with $F$. oxysporum f. sp. bacilici. Artificial inoculation tests of the selfed progeny indicated that the resistance of the rescued plants was inheritable. Consequently, a Fusarium-resistant cultivar, Nufar, was developed and registered in Israel (1). In recent years, other Fusariumresistant cultivars have been selected in Israel, but very little information is available on the genetic mechanism of resistance to $F$. oxysporum $\mathrm{f}$. sp. bacilici in sweet basil. The objective of the present research was to study the inheritance of resistance in Nufar sweet basil.

\section{MATERIALS AND METHODS}

Plant source and hybridization array. Two parent lines were used in this study: the resistant $P_{1}$ line, Nufar, was obtained by selection for resistance in four selfed generations of the resistant cv. Nufar (9), and the susceptible $\mathrm{P}_{2}$ line, Chen, a local cultivar originally introduced from the United States and reselected at Newe Ya'ar. In the first stage, parental lines were evaluated for resistance or susceptibility. The second stage included generation and evaluation of the reciprocal $F_{1}$ progeny and additional selfing of the parents. In the third stage, reciprocal $F_{2}$ populations and reciprocal backcross $\mathrm{BC}_{1} \mathrm{~F}_{1}$ populations were generated and evaluated.

Basil seed were planted in a 1:1 peat:vermiculite mix. Healthy 4- to 5week-old transplants, 7 to $10 \mathrm{~cm}$ in height, were used for inoculation tests.

Inoculum preparation. A virulent isolate of F. oxysporum f. sp. bacilici (MA48, Fusarium Research Center accession number 0-1042) that had been recovered from the stems of symptomatic Chen plants was grown on potato dextrose agar (PDA) for 10 days at $25^{\circ} \mathrm{C}$ in the dark. The inoculum was prepared by gently brushing plates flooded with sterile distilled water and filtering the conidial suspension through cheesecloth to remove mycelial and PDA fragments. The resulting suspension was diluted to obtain $5 \times 10^{6}$ conidia/ml, as determined with a hemacytometer. Each of the transplants at the three-leaflet stage was dipped in a conidial suspension for $5 \mathrm{~s}$ to soak the medium into the developed roots. Inoculated seedlings were planted in pots filled with 0.5 liter of sterile soil that had a composition of $58.2 \%$ clay, $23 \%$ silt, $18.8 \%$ sand, $2.1 \%$ organic matter, and $7.1 \% \mathrm{CaCO}_{3}$. Inoculated and noninoculated control plants were maintained in the greenhouse in a temperature regime of 15 to $18^{\circ} \mathrm{C}$ at night and 25 to $30^{\circ} \mathrm{C}$ during the day to allow symptoms to develop. Symptom development was followed in each plant for 80 days. Plants that wilted and defoliated were considered susceptible and plants that were symptom free were considered resistant The numbers and percentages of resistant and susceptible plants in each line and generation were recorded and calculated, and disease incidence was expressed as a percentage for each tested line.

Experimental design and statistical analysis. A completely randomized design was used, with 45 to 100 plants of each tested population. The fit to expected Mendelian segregations for $\mathrm{F}_{2}$ and $\mathrm{BC}_{1} \mathrm{~F}_{1}$ populations was analyzed by means of a $\chi^{2}$ test. 


\section{RESULTS AND DISCUSSION}

The inoculation tests of the resistant parent $\mathrm{P}_{1}$, Nufar, and the susceptible parent $\mathrm{P}_{2}$, Chen, confirmed that all the Nufar plants were resistant and all the Chen plants were susceptible to $F$. oxysporum $\mathrm{f}$. sp. bacilici (Table 1). The results of the resistance of Nufar to $F$. oxysporum f. sp. bacilici in this study confirm other field trials previously conducted at Newe Ya'ar (9). All the noninoculated control plants of the resistant parent remained symptomless, but 40 to $46.6 \%$ of the noninoculated control, susceptible Chen plants, showed typical symptoms of Fusarium wilt. The Fusarium wilt symptoms in the noninoculated susceptible plants apparently came from infected seed (4) or through natural infection by diseased plants in the greenhouse, which occurred during the trials. Seed for crossings were produced only from symptomless plants. It has been shown previously that basil plants might be infected during the growing season via aerial conidia (8).
The susceptible plants in the inoculation tests showed the first symptoms 10 to 14 days after inoculation; the first symptoms were detected on the apex parts of the plant and were characterized by an asymmetric, chlorotic, and distorted appearance of the leaves. After another 2 to 5 days, more apical leaves in lower stages of the plant showed symptoms of chlorosis and distortion accompanied by the appearance of necrosis on the leaves that showed symptoms first. In the next stage, vascular discoloration with necrotic lesions appeared on the main stem, then turned to dark longitudinal streaks on the stem and petioles and led to complete defoliation of the plant. The whole process was accompanied by a drastic growth retardation and led to wilting and death of all the susceptible plants 20 to 30 days after inoculation.

All reciprocal $F_{1}$ crosses and the first selfing generation $\left(S_{1}\right)$ of the parental lines were inoculated and evaluated for their resistance to $F$. oxysporum f. sp. bacilici (Table 1). The $S_{1}$ of the resistant parent
Nufar was homozygous for resistance and the susceptible parent Chen was homozygous for susceptibility to $F$. oxysporum $\mathrm{f}$. sp. bacilici. The data from reciprocal $F_{1}$ crosses also confirm that resistance to $F$. oxysporum f. sp. bacilici is controlled by one or more nuclear dominant genes.

The results of the inoculation tests of the $\mathrm{F}_{2}$ and $\mathrm{BC}_{1} \mathrm{~F}_{1}$ populations show that, in the $\mathrm{F}_{2}$ populations, the ratio of resistant to susceptible plants was 3:1 (Table 2). The segregation in all $\mathrm{BC}_{1} \mathrm{~F}_{1}$ populations that originated from a cross to the susceptible $\mathrm{S}_{1}$ line (Chen) revealed the expected 1:1 ratio (Table 2). These results correspond to a mode of inheritance of one autosomal gene with two alleles, with the dominant providing resistance to $F$. oxysporum $\mathrm{f}$. $\mathrm{sp}$. bacilici, and the recessive providing susceptibility. This mode of inheritance of resistance to Fusarium spp. has been detected previously in crops such as Lycopersicon esculentum, Pisum sativum, Cicer arietinum, Cucumis sativum, and Brassica oleracea (5). We designated this gene

Table 1. Inoculation test of parental, reciprocal $\mathrm{F}_{1}$, and first selfing generation $\left(\mathrm{S}_{1}\right)$ lines of basil plants inoculated with Fusarium oxysporum $\mathrm{f}$. sp. basilici

\begin{tabular}{|c|c|c|c|c|c|}
\hline \multirow[b]{2}{*}{ Tested generation $^{\mathrm{a}}$} & \multirow[b]{2}{*}{ Line, combination } & \multirow[b]{2}{*}{ Inoculation } & \multirow[b]{2}{*}{ Number of tested plants } & \multicolumn{2}{|c|}{ Diseased plants } \\
\hline & & & & Number & Percent \\
\hline $\mathrm{P}_{1}$ & Nufar & + & 100 & 0 & 0 \\
\hline $\mathrm{P}_{1}$ & Nufar & - & 50 & 0 & 0 \\
\hline $\mathrm{P}_{2}$ & Chen & + & 100 & 100 & 100 \\
\hline $\mathrm{P}_{2}$ & Chen & - & 50 & 20 & 40 \\
\hline $\mathrm{S}_{1(\mathrm{P} 1)}$ & Nufar & + & 60 & 0 & 0 \\
\hline $\mathrm{S}_{1(\mathrm{P} 1)}$ & Nufar & - & 60 & 0 & 0 \\
\hline $\mathrm{S}_{1(\mathrm{P} 2)}$ & Chen & + & 30 & 30 & 100 \\
\hline $\mathrm{S}_{1(\mathrm{P} 2)}$ & Chen & - & 30 & 14 & 46.6 \\
\hline $\mathrm{F}_{1}$ & q Chen $\times \precsim$ Nufar & + & 60 & 0 & 0 \\
\hline $\mathrm{F}_{1}$ & q Chen $\times \widehat{o}$ Nufar & - & 60 & 0 & 0 \\
\hline $\mathrm{F}_{1}$ & ㅇ Nufar $\times$ Chen & + & 60 & 0 & 0 \\
\hline $\mathrm{F}_{1}$ & o Nufar $\times>$ Chen & - & 60 & 0 & 0 \\
\hline
\end{tabular}

${ }^{a} \mathrm{P}_{1} / \mathrm{P}_{2}=$ parental generation; $\mathrm{S}_{1(\mathrm{P} 1)} / \mathrm{S}_{1(\mathrm{P} 2)}=$ selfcross of parental generation; and $\mathrm{F}_{1}=$ first generation from a cross between parents.

Table 2. Inoculation test of reciprocal $\mathrm{F}_{2}$ progenies and $\mathrm{BC}_{1} \mathrm{~F}_{1}$ lines of basil plants inoculated with Fusarium oxysporum f. sp. basilici

\begin{tabular}{|c|c|c|c|c|c|c|c|}
\hline \multirow[b]{2}{*}{ Tested generation $^{\mathbf{a}}$} & \multirow[b]{2}{*}{ Combination } & \multirow[b]{2}{*}{ Inoculation } & \multirow[b]{2}{*}{ No. of plants tested } & \multirow[b]{2}{*}{ Number } & \multicolumn{2}{|c|}{ Diseased plants } & \multirow[b]{2}{*}{$P(1 \mathrm{df})^{\mathrm{c}}$} \\
\hline & & & & & Percent & $\chi^{2 b}$ & \\
\hline $\mathrm{F}_{2}$ & o Chen $\times ð$ Nufar & + & 100 & 25 & 25 & 0 & 1.00 \\
\hline $\mathrm{F}_{2}$ & of Chen $\times \widehat{~ N u f a r}$ & - & 60 & 2 & 3.3 & $\ldots$ & $\ldots$ \\
\hline $\mathrm{F}_{2}$ & i Nufar $\times \delta$ Chen & + & 100 & 29 & 29 & 0.85 & 0.35 \\
\hline $\mathrm{F}_{2}$ & i Nufar $\times ð$ Chen & - & 60 & 3 & 5 & $\ldots$ & $\ldots$ \\
\hline $\mathrm{BC}_{1} \mathrm{~F}_{1}$ & $\mathrm{~F}_{1} \propto(q$ Chen $\times \widehat{\jmath}$ Nufar $) \times \delta$ Chen & + & 90 & 49 & 54.4 & 0.71 & 0.39 \\
\hline $\mathrm{BC}_{1} \mathrm{~F}_{1}$ & $\mathrm{~F}_{1}+(q$ Chen $\times \widehat{\diamond}$ Nufar $) \times \widehat{\delta}$ Chen & - & 40 & 4 & 10.5 & $\ldots$ & $\ldots$ \\
\hline $\mathrm{BC}_{1} \mathrm{~F}_{1}$ & $q$ Chen $\times \lesssim F_{1}(q$ Chen $\times \lesssim$ Nufar $)$ & + & 45 & 17 & 39.5 & 1.88 & 0.16 \\
\hline $\mathrm{BC}_{1} \mathrm{~F}_{1}$ & + Chen $\times \lesssim F_{1}(q$ Chen $\times \lesssim$ Nufar $)$ & - & 10 & 0 & 0 & $\ldots$ & $\ldots$ \\
\hline $\mathrm{BC}_{1} \mathrm{~F}_{1}$ & $q \mathrm{~F}_{1}(q$ Nufar $\times \circlearrowleft$ Chen $) \times \delta$ Chen & + & 70 & 39 & 55.7 & 0.91 & 0.33 \\
\hline $\mathrm{BC}_{1} \mathrm{~F}_{1}$ & $q \mathrm{~F}_{1}(q$ Nufar $\times \lesssim$ Chen $) \times \delta$ Chen & - & 34 & 5 & 14.7 & $\ldots$ & $\ldots$ \\
\hline $\mathrm{BC}_{1} \mathrm{~F}_{1}$ & + Chen $\times ð F_{1}(q$ Nufar $\times ð$ Chen $)$ & + & 75 & 35 & 46.6 & 0.33 & 0.56 \\
\hline $\mathrm{BC}_{1} \mathrm{~F}_{1}$ & 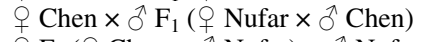 & - & 20 & 1 & 5 & $\ldots$ & $\ldots$ \\
\hline $\mathrm{BC}_{1} \mathrm{~F}_{1}$ & $q \mathrm{~F}_{1}(q$ Chen $\times \hat{\delta}$ Nufar $) \times \hat{\delta}$ Nufar & + & 100 & 0 & 0 & $\ldots$ & $\ldots$ \\
\hline $\mathrm{BC}_{1} \mathrm{~F}_{1}$ & $+\mathrm{F}_{1}(q$ Chen $\times \widehat{\delta}$ Nufar $) \times \widehat{\delta}$ Nufar & - & 60 & 0 & 0 & $\ldots$ & $\ldots$ \\
\hline $\mathrm{BC}_{1} \mathrm{~F}_{1}$ & q Nufar $\times \curvearrowright F_{1}(q$ Chen $\times \curvearrowright$ Nufar $)$ & + & 100 & 0 & 0 & $\ldots$ & $\ldots$ \\
\hline $\mathrm{BC}_{1} \mathrm{~F}_{1}$ & $q$ Nufar $\times ð F_{1}(q$ Chen $\times \lesssim$ Nufar $)$ & - & 60 & 0 & 0 & $\ldots$ & $\ldots$ \\
\hline $\mathrm{BC}_{1} \mathrm{~F}_{1}$ & $+\mathrm{F}_{1}(q$ Nufar $\times \lesssim$ Chen $) \times \delta$ Nufar & + & 100 & 0 & 0 & $\ldots$ & $\ldots$ \\
\hline $\mathrm{BC}_{1} \mathrm{~F}_{1}$ & $+\mathrm{F}_{1}(q$ Nufar $\times ð$ Chen $) \times \delta$ Nufar & - & 60 & 0 & 0 & $\ldots$ & $\ldots$ \\
\hline $\mathrm{BC}_{1} \mathrm{~F}_{1}$ & + Nufar $\times \precsim F_{1}(q$ Nufar $\times \precsim$ Chen $)$ & + & 100 & 0 & 0 & $\ldots$ & $\ldots$ \\
\hline $\mathrm{BC}_{1} \mathrm{~F}_{1}$ & $q$ Nufar $\times \mathrm{F}_{1} \precsim(q$ Nufar $\times \widehat{\delta}$ Chen $)$ & - & 60 & 0 & 0 & $\ldots$ & $\ldots$ \\
\hline
\end{tabular}

${ }^{a} \mathrm{~F}_{2}=$ second generation derived from a selfcross of $\mathrm{F}_{1} ; \mathrm{BC}_{1} \mathrm{~F}_{1}=$ backcross generation of $\mathrm{F}_{1}$ plants with first selfing generation $\left(\mathrm{S}_{1}\right)$ plants.

b $\chi^{2}$ was calculated for the expected ratios of 3:1 and $1: 1$ for $\mathrm{F}_{2}$ and $\mathrm{BC}$, respectively.

c $\alpha=0.05$. 
FOB-1; its dominant nature makes it a good candidate for introduction into new sweet basil hybrids and cultivars.

\section{ACKNOWLEDGMENTS}

We thank J. Katan for his helpful advice.

\section{LITERATURE CITED}

1. Dudai, N., Reuveni, R., and Putievsky, E. 1995. 'Nufar': A sweet basil variety, resistant to Fusarium wilt caused by Fusarium oxysporum f. sp. basilicum. Application for Registration No. 2376/95. Ministry of Agriculture, Israel Plant Breeders' Rights Council. Isr. Plant Breed. Gaz. 42:2.

2. Elmer, W. H., Wick, R. L., and Haviland, P. 1994. Vegetative compatibility among Fusarium oxysporum f. sp. basilicum isolates recovered from basil seed and infected plants. Plant Dis. 78:789-791.

3. Gamliel, A., Katan, T., Yunis, H., and Katan, J.
1996. Fusarium wilt and Crown rot of sweet basil: Involvement of soilborne and airborne inoculum. Phytopathology 86:56-61.

4. Garibaldi, A., Lodovica Gullino, M., and Minuto, G. 1997. Diseases of basil and their management. Plant Dis. 81:124-132

5. Goth, R. W., and Webb, R. E. 1981. Sources and genetics of host resistance in vegetable crops. Pages 377-411 in: Fungal Wilt Diseases of Plants. M. E. Mace, A. A. Bell, and C. H. Beckman, eds. Academic Press, New York.

6. Keinath, A. P. 1994. Pathogenicity and host range of Fusarium oxysporum from sweet basil and evaluation of disease control methods. Plant Dis. 78:1211-1215.

7. Minuto, A., Mocioni, M., and Garibaldi, A. 1995. Preliminary trials on biological control of Fusarium wilt of basil. Acta Hortic. 382:173-177.

8. Rekah, Y., Shtienberg, D., and Katan, J. 2000. Disease development following infection of tomato and basil foliage by airborne conidia of the soilborne pathogens Fusarium oxysporum f. sp. radicis-lycopersici and $F$. oxysporum $\mathrm{f}$. sp. basilici. Phytopathology 90:1322-1329.

9. Reuveni, R., Dudai, N., Putievsky, E., Elmer, W. H., and Wick, R.L. 1997. Evaluation and identification of basil germ plasm for resistance to Fusarium oxysporum f. sp. basilicum. Plant Dis. 81:1077-1081.

10. Ryding, O. 1994. Notes on the sweet basil and its wild relatives (Lamiaceae). Econ. Bot 48:65-67

11. Trueman, S. L., and Wick, R. L. 1996. Fusarium wilt of herbs. In: Proc. Int. Symp. Medicinal Aromatic Plants. L. E. Craker, L. Nolan, and K. Shetty, eds. Acta Hortic. 426:365-373.

12. Vergovskii, V. I. 1959. Some peculiarities in the development of fusariosis in basil. (In Russian). (Abstr.) Rev. Appl. Mycol. 38:613.

13. Wick, R. L., and Haviland, P. 1992. Occurrence of Fusarium wilt of basil in the United States. Plant Dis. 76:323. 